\title{
MÉTODOS DE ANÁLISE DE SULFETOS EM AMOSTRAS DE ROCHAS E SEDIMENTOS(1)
}

\author{
M. L. T. CORRÊA ${ }^{(2)}, J$. W. V. MELLO(3), \\ A. C. RIBEIRO(4) \& L. M. COSTA ${ }^{(3)}$
}

\begin{abstract}
RESUMO
O presente trabalho foi realizado no período de agosto a dezembro de 1998, com o objetivo de comparar métodos de análise de sulfetos, visando obter uma técnica rápida, exata e reprodutível para avaliar o potencial de drenagem ácida em rochas e sedimentos. As amostras foram submetidas a digestões oxidativas com $\mathrm{H}_{2} \mathrm{O}_{2}$ e água régia. Nos extratos, foram determinados o $\mathrm{S}$ por gravimetria, por meio do Ba remanescente por espectrofotometria de absorção atômica (EAA), por turbidimetria e por colorimetria. Os teores de $\mathrm{Fe} \mathrm{e} \mathrm{Pb}$ foram determi nados por EAA. Nos extratos de $\mathrm{H}_{2} \mathrm{O}_{2}$, determinou-se, também, a acidez por titulação com $\mathrm{NaOH}$. A técnica mais indicada para avaliar o teor de sulfetos foi a digestão das amostras com água régia, seguida da determi nação indireta do $\mathrm{S}$, por meio do Ba remanescente por EAA. A digestão com $\mathrm{H}_{2} \mathrm{O}_{2}$ não foi eficiente para a oxidação total dos sulfetos presentes nas amostras, devendo subestimar o potencial de geração da drenagem ácida em amostras de rochas e sedimentos.
\end{abstract}

Termos de indexação: drenagem ácida, potencial de acidificação, oxidação de sulfetos, técnicas analíticas de $\mathrm{S}$.

(1) Parte da Tese de Mestrado do primeiro autor, apresentada à Universidade Federal de Viçosa - UFV. Realizado com auxílio do CNPq e FAPEMIG. Recebido para publicação em janeiro de 2001 e aprovado em outubro de 2001.

(2) Doutorando do Departamento de Sol os da Universidade Federal de Viçosa - UFV. Av. P.H. Rolfs, s/n, CEP 36571-000 Viçosa (MG). E-mail: mauro@solos.ufv.br

(3) Professor do Departamento de Solos, UFV. Bolsista do CNPq. E-mails: jwvmello@mail.ufv.br; liovando@solos.ufv.br

(4) Professor titular aposentado do Departamento de Solos, UFV. E-mail: aribeiro@mail.ufv.br 


\title{
SUMMARY: METHODS OF SULFIDE ANALYSIS IN ROCKS AND SEDIMENTS
}

\begin{abstract}
This work was carried out to study methods of sulfideanalysis to obtain a fast, accurate and reproduci bleprocedureto evaluateacid drainagein samples of rocks and sediments. The samples were submitted to oxidative digestions with $\mathrm{H}_{2} \mathrm{O}_{2}$ and nitric-hydrochloric acid solutions (3:1, v/ v). TheS in theextracts was determined by gravi metry, atomic absorption spectrophotometry (AAS) for remaining $\mathrm{Ba}$, turbidimetry and col orimetry. The Feand $\mathrm{Pb}$ contents in the extracts were determined by AAS. Acidity was al so determined by titration with $\mathrm{NaOH}$ in the $\mathrm{H}_{2} \mathrm{O}_{2}$ extracts. Thenitric-hydrochl oric oxidativedigestion foll owed by $\mathrm{S}$ determination by AAS for remaining $\mathrm{Ba}$, after $\mathrm{BaCl}_{2}$ treatment of theextracts, was themost suitable technique for measuring the sulfide contents of the samples. On the other hand, $\mathrm{H}_{2} \mathrm{O}_{2}$ digestion was not efficient for the total oxi dation of the sulfides, underestimating the acid drainage potential in rock and sediment samples.
\end{abstract}

Index terms: acid drainage, potential acidity, sulfide oxidation, $\mathrm{S}$ analytical techniques.

\section{INTRODUÇÃO}

A presença de compostos sulfetados associados ao carvão mineral e a minérios, como de níquel, chumbo, zinco, cobre, urânio, ouro e prata, pode provocar a drenagem ácida que constitui um dos mais sérios problemas de cunho ambiental.

A atividade mineradora expõe à atmosfera os sulfetos que, ao entrarem em contato com a água e ar, oxidam-se, formando soluções ácidas. Essas soluções promovem a solubilização e mobilização de metais pesados que se encontram presentes no meio, os quais são lixiviados ao longo do perfil. Desta forma, esses elementos químicos, nocivos aos seres vivos, podem afetar a saúde humana via cadeia trófica.

Existem, descritos na literatura, vários métodos de análises de enxofre, como os desenvolvidos por J ohson \& Nishita (1952), Beaton et al. (1968), Aspiras et al . (1972), Sorensen et al . (1979), Schiavon \& Zotti (1995), Tseet al. (1995), dentre outros. Alguns deles têm sido utilizados com o propósito de avaliar o potencial de drenagem ácida. Neste particular, o método analítico que tem recebido maior destaque foi proposto por O'Shay et al . (1990), que utiliza $\mathrm{H}_{2} \mathrm{O}_{2}$ como agente oxidante e determina a acidez gerada por titulação com base forte.

Todavia, até o momento, não se encontram na literatura relatos sobre a utilização desta técnica aplicada a substratos sulfetados encontrados no Brasil. Soares (1995) utilizou água régia para oxidar sulfetos em amostras provenientes do complexo carbo-energético de Candiota (RS) e determinou o sulfato dos extratos por gravimetria. Contudo, testes quanto à exati dão e precisão desta técnica não foram realizados. Além disso, segundo Beaton et al. (1968), a técnica gravimétrica étrabalhosa, demorada e, em alguns casos, apresenta precisão inaceitável.

O presente trabal ho objetivou estudar alguns métodos para análise de sulfetos após sua oxidação a sulfatos, com vistas em obter um método rápido, exato e reprodutível para avaliar a drenagem ácida em amostras de rochas e sedimentos.

\section{MATERIAL E MÉTODOS}

Dezoitoamostras demateriais sulfetados, oriundas de diversos estados do Brasil (Quadro 1), foram selecionadas ecaracterizadas mineral ogicamentepor difração de rai os-X, utilizando difratômetro Rigaku, radiação Cu-Ka com filtro de níquel. Para tanto, foram trituradas, peneiradas, visando obter partículas inferiores a $149 \mu \mathrm{m}$ (<100 mesh), e acondicionadas em lâminas escavadas. A identificação dos minerais foi efetuada, conforme J oint Committee on Powder Difraction Standards (1974).

\section{Digestões oxidativas (via úmida)}

Digestão das amostras por água régia - Esta extração, em cinco repetições, foi realizada segundo método descrito por Soares (1995), com algumas adaptações e constou das seguintes etapas:

a) Foram pesados $8,00 \mathrm{~g}$ de cada amostra ( $<149 \mu \mathrm{m})$ em erlenmeyers de $250 \mathrm{~mL}$ eagitados a $180 \mathrm{rpm}$ com $100 \mathrm{~mL}$ de $\mathrm{CaCl}_{2} 1 \mathrm{~mol} \mathrm{~L}-1$, por $30 \mathrm{~min}$. A suspensão obtida foi filtrada a vácuo, utilizando papel defiltraçãolenta, e o material sólido retido no papel de filtro foi lavado com $200 \mathrm{~mL}$ de água destilada, visando eliminar o sulfato porventura presente na amostra. 


\section{Quadro 1. I dentificação, procedência e composição mineralógica das amostras, conforme J OINT COMMITTEE ON POWDER DIFRACTION STANDARDS (1974)}

\begin{tabular}{|c|c|c|c|}
\hline Amostra & Descrição & Procedência & Composição mineralógica \\
\hline$P$ & Mineral padrão $\left(\mathrm{FeS}_{2}\right)$ & Ouro Preto (MG) & Marcassita e pirita \\
\hline 1 & Material piritoso de mineração de carvão & Candiota (RS) & Calcopirita, esfalerita, marcassita e pirita \\
\hline 2 & Estéril de mineração de carvão & Candiota (RS) & Coquimbita, marcassita, pirita e titanita \\
\hline 3 & $\begin{array}{l}\text { Concentrado de sulfetos de mineração de } \\
\text { ouro }\end{array}$ & Raposos (MG) & Dolomita, marcassita, pirita, quartzo e siderita \\
\hline 4 & Material piritoso de mineração de carvão & Candiota (RS) & $\begin{array}{l}\text { Calcopirita, esfalerita, grafite, marcassita, pirita } \\
\text { e quartzo }\end{array}$ \\
\hline 5 & Minério de ouro & Sabará (MG) & $\begin{array}{l}\text { Calcita, dolomita, esfalerita, pirita, quartzo e } \\
\text { siderita }\end{array}$ \\
\hline 6 & Minério de chumbo & Canguçu (RS) & Galena e quartzo \\
\hline 7 & Rejeito de mineração de ouro & Raposos (MG) & $\begin{array}{l}\text { Calcosiderita, dolomita, esfalerita, quartzo e } \\
\text { siderita }\end{array}$ \\
\hline 8 & Minério de ouro & Raposos (MG) & $\begin{array}{l}\text { Calcopirita, caulinita, esfalerita, lizardita, } \\
\text { quartzo e siderita }\end{array}$ \\
\hline 9 & $\begin{array}{l}\text { Solo tiomórfico (coletado a } 70-80 \mathrm{~cm} \text { de } \\
\text { profundidade) }\end{array}$ & Campos (RJ) & Caulinita, jarosita, quartzo e romerita \\
\hline 10 & $\begin{array}{l}\text { Rejeito de mineração de ouro (depositado } \\
\text { a } 1 \text { ano) }\end{array}$ & Raposos (MG) & Calcosiderita, forsterita, quartzo e siderita \\
\hline 11 & Minério de ouro & Paracatu (MG) & Cal cosita, forsterita, quartzo e siderita \\
\hline 12 & $\begin{array}{l}\text { Rejeito de mineração de carvão } \\
\text { (granulometria }>4 \mathrm{~mm} \text { ) }\end{array}$ & Butiá (RS) & Caulinita, jarosita, pirita e quartzo \\
\hline 13 & $\begin{array}{l}\text { Rejeito de mineração de carvão } \\
\text { (granulometria }<4 \mathrm{~mm} \text { ) }\end{array}$ & Butiá (RS) & $\begin{array}{l}\text { Barita, cal cosiderita, caulinita, grafite, ilita, } \\
\text { micas e quartzo }\end{array}$ \\
\hline 14 & Estéril de carvão (exposto a 12 anos) & Candiota (RS) & Barita, caulinita, ilita, jarosita, micas e quartzo \\
\hline 15 & Estéril de carvão (exposto a 2 anos) & Candiota (RS) & Barita, caulinita, ilita, jarosita, micas e quartzo \\
\hline 16 & Estéril de carvão & Palermo (RS) & Barita, caulinita, ilita, quartzo e titanita \\
\hline 17 & Minério de ouro & Raposos (MG) & quartzo \\
\hline
\end{tabular}

b) O material retido no papel de filtro foi seco em estufa com circulação de ar a $40^{\circ} \mathrm{C}$, por $24 \mathrm{~h}$.

c) Amostras de $1,00 \mathrm{~g}$ deste material foram transferidas para balão de fundo chato de $500 \mathrm{~mL}$, adicionando-se $50 \mathrm{~mL}$ deágua régia $\left(1 \mathrm{HCl}: 3 \mathrm{HNO}_{3}\right.$, $\mathrm{v} / \mathrm{v})$. O material foi fervido por $30 \mathrm{~min}$, usando condensador de refluxo. Notopo do condensador, foi colocada uma tira de papel de filtro embebido em acetato de chumbo 0,1 mol L-1, como indicador da volatilização do sulfeto.

d) Após esfriar, foram adicionados $50 \mathrm{~mL}$ de água destilada e a suspensão foi filtrada, utilizando papel de filtração lenta. O material presente no papel de filtro foi lavado com água destilada para balão volumétrico de $250 \mathrm{~mL}$, depois completouse o volume com água destilada.
Digestão das amostras por $\mathbf{H}_{2} \mathbf{O}_{\mathbf{2}} \mathbf{3 0} \%$ - Antes de iniciar esta digestão, foi necessário identificar as amostras que apresentaram sinais de volatilização de sulfetos quando foram previamente lavadas com $\mathrm{HCl} 6,0 \mathrm{~mol} \mathrm{~L}^{-1}$ a $180 \mathrm{rpm}$ por $2 \mathrm{~h}$. Este procedimento visava eliminar os carbonatos, porventura presentes na amostra, segundo o método proposto por O'Shay et al. (1990).

Em frascos tipo americano de $50 \mathrm{~mL}$, foram colocados $2,00 \mathrm{~g}$ de cada amostra e $10 \mathrm{~mL}$ de $\mathrm{HCl}$ $6,0 \mathrm{~mol} \mathrm{~L}^{-1}$. I mediatamente, os frascos foram tampados com papel de filtro previamenteembebido em acetato de chumbo 0,1 mol $\mathrm{L}^{-1}$. Após $4 \mathrm{~h}$, foram avaliados os resultados (em caso de vol atilização de sulfeto, este reagiria com o acetato dechumbo, contido no papel, formando sul feto de chumbo, decor escura). 
Seguem-se abaixo os passos da técnica em que se utilizou o $\mathrm{H}_{2} \mathrm{O}_{2}$ como oxidante, em cinco repetições, conforme proposto por O'Shay et al. (1990), com adaptações:

a) Foram pesados $8,00 \mathrm{~g}$ decada amostra ( $<149 \mu \mathrm{m})$ em erlenmeyers de $250 \mathrm{~mL}$. As amostras que apresentaram resultado negativo para oteste de volatilização de sulfetos foram agitadas a 180 rpm com $160 \mathrm{~mL}$ de $\mathrm{HCl} 6,0 \mathrm{~mol} \mathrm{~L}^{-1}$ por $2 \mathrm{~h}$. As amostras que apresentaram resultado positivo para vol atilização de sulfetos for am agitadas com $100 \mathrm{~mL}$ de $\mathrm{CaCl}_{2} 1,0 \mathrm{~mol} \mathrm{~L}^{-1}$, também por $2 \mathrm{~h}$, na mesma rotação que as demais.

b) A suspensão foi filtrada a vácuo, utilizando papel de filtração lenta, enquanto o material retido no papel de filtro foi lavado com $500 \mathrm{~mL}$ de solução de $\mathrm{CaCl}_{2}$ 1,0 mol L-1. As etapas (a) e (b) visaram eliminar carbonatos e sulfatos porventura presentes na amostra;

c) O material retido no papel de filtro foi seco em estufa com circulação de ar a $40^{\circ} \mathrm{C}$, por $24 \mathrm{~h}$.

d) Foram pesados, precisamente, entre 0,02 e 0,50 g do material seco, dependendo do teor aproximado de sul fetos de cada amostra, transferindo-se para erlenmeyers de $500 \mathrm{~mL}$, onde foram adicionados, lentamente, $100 \mathrm{~mL}$ de $\mathrm{H}_{2} \mathrm{O}_{2} 30 \%$. A adiçãolenta do $\mathrm{H}_{2} \mathrm{O}_{2}$ foi necessária para evitar 0 borbulhamento excessivo da suspensão.

e) A suspensão foi levada à ebulição por $60 \mathrm{~min}$, com condensador de refluxo acoplado aos erlenmeyers. Após este tempo, adicionaram-se mais $50 \mathrm{~mL}$ de $\mathrm{H}_{2} \mathrm{O}_{2} 30 \%$ e a suspensão foi novamente levada à ebulição por mais 60 min, para garantir a total oxidação dos sulfetos.

f) Após esfriar à temperatura ambiente, adicionouse, lentamente, $1,0 \mathrm{~mL}$ de solução de $\mathrm{CuCl}_{2}$ $0,0157 \mathrm{~mol} \mathrm{~L}^{-1}$ (para eliminar o excesso de $\mathrm{H}_{2} \mathrm{O}_{2}$ ). Nesta etapa, foi utilizada $\mathrm{H}_{2} \mathrm{O}$ a $8^{\circ} \mathrm{C}$ para resfriar os erlenmeyers, que foram levados, novamente, à ebulição, por 15 min, para garantir a completa decomposição da $\mathrm{H}_{2} \mathrm{O}_{2}$.

g) Após resfriada à temperatura ambiente, a suspensão foi filtrada, utilizando papel de filtração lenta. O material presente no papel de filtro foi lavado com solução de $\mathrm{CaCl}_{2} 1,0 \mathrm{~mol} \mathrm{~L}^{-1}$. O lixiviado foi coletado em balão de $200 \mathrm{~mL}$, completando-se o volume com $\mathrm{CaCl}_{2} 1,0 \mathrm{~mol} \mathrm{~L}^{-1}$.

\section{Determinações}

Nos extratos obtidos a partir das digestões oxidativas, foram determinados os teores de S, Fee $\mathrm{Pb}$, de acordo com as marchas analíticas descritas a seguir. Além disso, foi determinada a acidez, por titulação com NaOH $0,01 \mathrm{~mol} \mathrm{~L}^{-1}$ (padronizado e isento de $\mathrm{CO}_{2}$ ), nos extratos da digestão por $\mathrm{H}_{2} \mathrm{O}_{2}$.
Determinação indireta de S, por meio do Ba remanescente por espectrofotometria de absorção atômica (EAA):

a) Foram pipetadas alíquotas de 1 a $10 \mathrm{~mL}$ dos extratos e $10 \mathrm{~mL}$ da prova em branco, para erlenmeyer de $125 \mathrm{~mL}$. Alíquotas dos extratos com volume inferior a $10 \mathrm{~mL}$ foram diluídas com solução da prova em branco suficiente para atingir o volume final de $10 \mathrm{~mL}$. A prova em branco contém todos os reagentes utilizados na extração, menos a amostra.

b) Os erlenmeyers foram aquecidos até início de ebulição, quando foram adicionados exata e lentamente $10 \mathrm{~mL}$ de $\mathrm{BaCl}_{2}$ 0,01 $\mathrm{mol} \mathrm{L}^{-1}$. Em seguida, procedeu-se à agitação por $30 \mathrm{~min}$ e repouso por $24 \mathrm{~h}$, para garantir a completa precipitação do $\mathrm{BaSO}_{4}$.

c) As suspensões foram filtradas para balão volumétrico de $100 \mathrm{~mL}$ em papel de filtração lenta. Cada unidade foi lavada com pequenas porções de água quente, utilizando uma piseta, até à proximidade da marca de $100 \mathrm{~mL}$ de cada balão. Após esfriar, completou-se o volume com água destilada.

d) Os extratos de $\mathrm{Ba}$ remanescente dos balões volumétricos foram homogeneizados e destes extraiu-se uma alíquota de $5 \mathrm{~mL}$, que foi transferida para balão volumétrico de $25 \mathrm{~mL}$, completando-se o volume com uma solução de $\mathrm{KCl} 2.500 \mathrm{mg} \mathrm{L}^{-1}$. E stas soluções foram levadas para leitura em EAA marca GBC model o 908 AA, utilizando chama $\mathrm{N}_{2} \mathrm{O} / \mathrm{C}_{2} \mathrm{H}_{2}$, juntamente com a curva de calibração.

O teor de $\mathrm{S}$ das amostras foi calculado por meio da fórmula:

$\mathrm{S}=([\mathrm{Ba}]-[\mathrm{X}]) \mathrm{MS}_{1} \mathrm{~V}_{2} \mathrm{~V}_{3} / 10.000 \mathrm{~A}_{1} \mathrm{~A}_{2} \operatorname{Mam} \mathrm{MBa}(1)$ em que:

$\mathrm{S}=$ teor de enxofre das amostras (em dag kg${ }^{-1}$ );

[Ba] = concentração média de $\mathrm{Ba}$, na solução, referente à prova em branco $\left(\mathrm{mol} \mathrm{L}^{-1}\right)$;

$[X]=$ concentração de $B a$, na solução, referenteà amostra (mol L-1);

$\mathrm{V}_{1}=$ volume final da solução após digestão oxidativa $(\mathrm{mL})$;

$\mathrm{V}_{2}=$ vol ume da solução após o tratamento com a solução de $\mathrm{BaCl}_{2}$ 0,01 mol L-1 (item c) (mL);

$\mathrm{V}_{3}=$ volume final da solução de leitura (item d) $(\mathrm{mL})$;

$\mathrm{A}_{1}=$ alíquota da solução digerida à qual foi adicionada a solução de $\mathrm{BaCl}_{2} \quad 0,01 \mathrm{~mol} \mathrm{~L}^{-1}$ (item a) (mL);

$\mathrm{A}_{2}=$ alíquota à qual foi adicionada a solução de $\mathrm{KCl} 2.500 \mathrm{mg} \mathrm{L}^{-1}$ para leitura (item d) $(\mathrm{mL})$; 
Mam = massa da amostra corrigida(depois de seca a $\left.105^{\circ} \mathrm{C}\right)(\mathrm{g})$;

MS = massa atômica do enxofre;

$\mathrm{MBa}=$ massa atômica do Ba;

10.000 = fator de transformação de $\mathrm{mg} \mathrm{L}^{-1}$ para dag $\mathrm{kg}^{-1}$.

Determinação de S por gravimetria: Foi utilizada a técnica descrita por Soares (1995), com al gumas adaptações:

a) Foram pipetados $50 \mathrm{~mL}$ dos extratos, para erlenmeyer de $125 \mathrm{~mL}$, adicionando-se 10 gotas de $\mathrm{HNO}_{3}$ concentrado.

b) O conjunto foi aquecido até o início da ebulição, quando foram adicionados, gota a gota, $10 \mathrm{~mL}$ de solução de $\mathrm{BaCl}_{2} \quad 0,35 \mathrm{~mol} \mathrm{~L}^{-1}$. Os erlenmeyers foram agitados a $180 \mathrm{rpm}$ durante $30 \mathrm{~min}$ e, em seguida, mantidos em repouso atéo dia seguinte, para que se completasse a preci pitação do sulfato de bário $\left(\mathrm{BaSO}_{4}\right)$.

c) O extrato foi filtrado em papel de filtração lenta e lavado com água quente até que o filtrado não apresentasse reação com $\mathrm{AgNO}_{3}$ a $50 \mathrm{~g} \mathrm{~L}^{-1}$.

d) O papel de filtro com o precipitado foi calcinado a $750^{\circ} \mathrm{C}$.

e) Após esfriar, em dessecador, o conjunto (cadinho + cinza) foi pesado em balança analítica.

O teor de enxofre das amostras foi calculado, utilizando-se a fórmula:

$$
\mathrm{S}=100 \mathrm{MS} \mathrm{V}_{1} \mathrm{Mppt} / \mathrm{MBaSO}_{4} \mathrm{~V}_{2} \mathrm{Mam}
$$
em que:

$\mathrm{S}=$ teor de enxofre das amostras (em dag $\mathrm{kg}^{-1}$ );

100 = fator de conversão para dag kg-1;

$\mathrm{MS}=$ massa atômica do $\mathrm{S}$;

$\mathrm{MBaSO}_{4}=$ massa molecular do $\mathrm{BaSO}_{4} ;$

$\mathrm{V}_{1}=$ volume final da solução após digestão oxidativa $(\mathrm{mL})$;

$\mathrm{V}_{2}=$ volume de alíquota em que se adicionou a solução de $\mathrm{BaCl}_{2}$ 0,35 $\mathrm{mol} \mathrm{L}^{-1}(\mathrm{~mL})$;

$\mathrm{Mppt}=$ massa do precipitado de $\mathrm{BaSO}_{4}$ isenta de umidade (g);

Mam = massa da amostra corrigida (depois de seca a $\left.105^{\circ} \mathrm{C}\right)(\mathrm{g})$.

Determinação de S por turbidimetria: NoS extratos deágua régia, foi utilizada a técnica descrita por Blanchar et al. (1965). Nos extratos de $\mathrm{H}_{2} \mathrm{O}_{2}$, utilizou-se a técnica descrita por Alvarez $\mathrm{V}$. et al. (2001), para determinações turbidimétricas de S em extratos de solo.

Determinação de S por espectrofotometria do visível: Foi utilizada a técnica proposta por Nemeth (1964), conforme descrito por Palaskar et al. (1981). Esta técnica foi utilizada apenas para os extratos de água régia e teve como princípio a eliminação, por precipitação, do sulfato da solução como sulfato de bário. Neste caso, foi usado o cromato de bário em vez de $\mathrm{BaCl}_{2}$ em ácido clorídrico diluído, ocorrendo a produção ou liberação do íon cromato (amarelo) em um total equivalente ao íon sulfato precipitado, conforme a reação:

$$
\mathrm{SO}_{4}^{2-}+\mathrm{BaCrO}_{4} \Leftrightarrow \mathrm{BaSO}_{4}+\mathrm{CrO}_{4}^{2-}
$$

Em meio ácido $\left(\mathrm{HCl} 1,5 \mathrm{~mol} \mathrm{~L}^{-1}\right)$, o cromato foi convertido a dicromato, conforme a equação:

$$
2 \mathrm{CrO}_{4}^{2-}+\mathrm{H}^{+} \Leftrightarrow \mathrm{Cr}_{2} \mathrm{O}_{7}^{2-}+\mathrm{OH}^{-}
$$

Depois da precipitação do sulfato de bário, o excesso de cromato de bário foi insolubilizado por uma solução amoniacal e o íon dicromato livre novamente convertido à forma de cromato. Os preci pitados de sulfato de bário e cromato de bário foram eliminados por filtração, originando uma sol ução de col oração amarel ada, cuja intensi dade de cor produzida foi diretamente proporcional à concentração de sulfato na alíquota.

Determinação de $\mathbf{F e} \mathbf{e} \mathbf{P b}$ : Foram retiradas alíquotas dos extratos, que, após devidamente diluídas e, juntamentecom as respectivas curvas de calibração, foram levadas à leitura para determinação de ferro e chumbo EAA (marca GBC modelo 908 AA).

\section{RESULTADOS E DISCUSSÃO}

\section{Mineralogia das amostras}

As amostras P, 1, 2, 3, 4, 5, 8 e 12 apresentaram sulfetos de ferro, sendo, portanto, potencialmente geradoras de drenagem ácida (Quadro 1). Destas, as amostras 3, 5 e 8 apresentaram, também, carbonatos que podem, pelo menos parcialmente, contrabalançar a acidez gerada pela oxidação dos sulfetos.

As amostras 6, 7, 10 e 11 apresentaram sulfetos, porém de $\mathrm{Pb}$ (gal ena), Zn (esfal erita) eCu (calcocita), cuja oxidação, segundo I ngri (1996), não deve gerar acidez. A amostra 7 apresentou, ainda, carbonatos (dolomita e siderita). As amostras 10 e 11 apresentaram siderita, cuja dissol ução produz solução final neutra (Mello \& Abrahão, 1998).

As amostras 9, 13, 14, 15 e 16 não apresentaram sulfetos, apenas sulfatos (barita, jarosita e romerita) enão geraram acidez. Não foram detectados, para a amostra 17, outros minerais, além de quartzo.

\section{Teores de S nos extratos de água régia}

Comparando os teores de $\mathrm{S}$, obtidos pelas quatro diferentes técnicas de determinação de S (Quadro 2) 
utilizadas, com os valores teóricos $(53,45 \%$ de $\mathrm{S}$ e $46,55 \%$ de $\mathrm{Fe}$ ) para a amostra-padrão (P) de $\mathrm{FeS}_{2}$, verificou-se que as técnicas: gravimétrica, de determinação indireta de $\mathrm{S}$ por meio do $\mathrm{Ba}$ remanescente por EAA eturbidimétrica apresentaram mai or exatidão. Dentre estas três técnicas, a gravimétrica e de determinação do Ba remanescente por EAA foram mais precisas, pois apresentaram menor desvio-padrão das médias para a amostrapadrão (Quadro 2).

A técnica gravimétrica apresentou amplitude de recuperação entre 101,53 e 103,74\% doS teoricamente contido na amostra-padrão (P). Mostrou-se eficaz para determinação de $\mathrm{S}$ em amostras com altas concentrações. Para amostras com baixos teores de $\mathrm{S}$, porém, os desvios-padrão das médias foram maiores que os observados para as determinações por EAA. U ma alternativa para aumentar a precisão da técnica gravimétrica seria adotar amostras maiores. Contudo, a relação entre o volume de água régia e a massa de amostra deve ser considerada com cautela, pois amostras muito grandes e ricas em material orgânico podem levar a uma digestão incompleta e, conseqüentemente, a resultados errôneos. Apesar desatisfatória, para amostras com altoteor deS, a técnica gravimétrica foi considerada muito trabal hosa e demorada.

A técnica de determinação indireta deS, por meio do $\mathrm{Ba}$ remanescente por EAA apresentou uma amplitude de recuperação entre 97,25 e 100,34\% do S teoricamente contidona amostra-padrão (P). Além disto, verificou-se que esta técnica apresentou, de modo geral, menor amplitude de variação para o C.V. (Figura 1).

As amostras 15, 16 e 17 apresentaram valores nulos de $S$, para a técnica de EAA, na diluição utilizada, condizente com a sua mineralogia (Quadro 1), queindicou a ausência de sulfetos. Devese, no entanto, ressaltar que estes valores não indicam ausência de sulfetos nestas amostras, dada a possibilidade de terem sido os extratos muito diluídos. Para estes casos, devem ser tomadas diluições menores ou amostras de maior massa.

A turbidimetria mostrou-se menos precisa com relação à gravimetria eEAA (Figura 1). A amplitude derecuperação deS pela turbidimetria variou de 87,48 a 100,36\% com relação ao valor teórico de S na amostra-padrão(P). Deve-seconsiderar quea condição ideal para determi nação de $S$ por esta técnica ocorre numa faixa de $\mathrm{pH}$ entre 3,0 e 3,3. A faixa de $\mathrm{pH}$ das suspensões de leitura para os extratos deágua régia variaram de 0,6 a 0,7; portanto, muito aquém da condição ideal. Relata-se, ainda, que esta condição adversa não pode ser contornada durante o processo analítico. Quando se tentou ajustar o pH das amostras à faixa ideal para a adição do $\mathrm{BaCl}_{2}$, verificou-se a formação de precipitado marromescuro, presumivel menteóxidos hidratados deferro, o que indubitavelmente superestimaria os valores de $\mathrm{S}$ obtidos. Os equilíbrios de Fe mostrados por Lindsay (1979) indicam a precipitação de $\mathrm{Fe}(\mathrm{OH})_{3}$ com oaumento do pH. Como existe alta concentração

Quadro 2. Teores de S determi nados por gravi metria, indiretamente por meio do Ba remanescente por EAA, turbidimetria e colorimetria, nos extratos de água régia

\begin{tabular}{ccccc}
\hline \multirow{2}{*}{ Amostra } & Gravimetria & Ba remanescente & Turbidimetria & Colorimetria \\
\hline & & & Média $\pm \mathrm{S}_{\bar{y}}(1)$, dag kg-1 & \\
\cline { 2 - 5 } & & & & \\
1 & $54,98 \pm 0,22 \mathrm{Aa}$ & $53,04 \pm 0,40 \mathrm{Aa}$ & $50,21 \pm 1,27 \mathrm{Aa}$ & $39,19 \pm 2,29 \mathrm{Ba}$ \\
2 & $50,41 \pm 0,16 \mathrm{Aa}$ & $52,40 \pm 0,33 \mathrm{Aa}$ & $49,25 \pm 1,14 \mathrm{Aa}$ & $34,10 \pm 1,37 \mathrm{Ba}$ \\
3 & $46,12 \pm 0,27 \mathrm{Aa}$ & $41,69 \pm 0,44 \mathrm{Ab}$ & $41,67 \pm 1,05 \mathrm{Aa}$ & $32,72 \pm 3,19 \mathrm{Bab}$ \\
4 & $34,74 \pm 0,24 \mathrm{Ab}$ & $40,57 \pm 0,21 \mathrm{Ab}$ & $26,37 \pm 2,69 \mathrm{Bb}$ & $25,11 \pm 2,50 \mathrm{Bb}$ \\
5 & $23,67 \pm 0,20 \mathrm{Ac}$ & $26,16 \pm 0,51 \mathrm{Ac}$ & $21,10 \pm 0,73 \mathrm{ABbc}$ & $15,98 \pm 1,36 \mathrm{Bc}$ \\
6 & $17,96 \pm 0,18 \mathrm{Ac}$ & $13,24 \pm 0,14 \mathrm{ABd}$ & $15,49 \pm 0,25 \mathrm{ABc}$ & $10,51 \pm 0,80 \mathrm{Bcde}$ \\
7 & $15,14 \pm 0,18 \mathrm{Ac}$ & $10,12 \pm 0,22 \mathrm{Ade}$ & $13,44 \pm 0,42 \mathrm{Ac}$ & $15,06 \pm 1,90 \mathrm{Acd}$ \\
8 & $5,05 \pm 0,11 \mathrm{Ad}$ & $5,16 \pm 0,06 \mathrm{Adef}$ & $2,55 \pm 0,29 \mathrm{Ad}$ & $6,27 \pm 0,78 \mathrm{Adef}$ \\
9 & $3,22 \pm 0,06 \mathrm{Ad}$ & $4,70 \pm 0,08 \mathrm{Adef}$ & $1,93 \pm 0,11 \mathrm{Ad}$ & $4,81 \pm 0,53 \mathrm{Aef}$ \\
10 & $2,16 \pm 0,07 \mathrm{Ad}$ & $3,83 \pm 0,05 \mathrm{Aef}$ & $1,17 \pm 0,10 \mathrm{Ad}$ & $3,19 \pm 0,32 \mathrm{Aef}$ \\
11 & $2,77 \pm 0,06 \mathrm{Ad}$ & $3,07 \pm 0,05 \mathrm{Aef}$ & $2,02 \pm 0,03 \mathrm{Ad}$ & $3,46 \pm 0,50 \mathrm{Aef}$ \\
12 & $1,31 \pm 0,06 \mathrm{Ad}$ & $2,87 \pm 0,04 \mathrm{Aef}$ & $0,55 \pm 0,04 \mathrm{Ad}$ & $3,21 \pm 0,60 \mathrm{Aef}$ \\
13 & $3,58 \pm 0,09 \mathrm{Ad}$ & $2,78 \pm 0,04 \mathrm{Aef}$ & $1,91 \pm 0,17 \mathrm{Ad}$ & $4,12 \pm 0,53 \mathrm{Aef}$ \\
14 & $1,25 \pm 0,10 \mathrm{Ad}$ & $0,72 \pm 0,01 \mathrm{Af}$ & $0,41 \pm 0,02 \mathrm{Ad}$ & $2,63 \pm 0,62 \mathrm{Aef}$ \\
15 & $1,29 \pm 0,06 \mathrm{Ad}$ & $0,20 \pm 0,01 \mathrm{Af}$ & $0,38 \pm 0,02 \mathrm{Ad}$ & $2,09 \pm 0,47 \mathrm{Aef}$ \\
16 & $0,85 \pm 0,09 \mathrm{Ad}$ & $0,00 \pm 0,00 \mathrm{Af}$ & $0,20 \pm 0,01 \mathrm{Ad}$ & $1,10 \pm 0,60 \mathrm{Af}$ \\
17 & $0,98 \pm 0,08 \mathrm{Ad}$ & $0,00 \pm 0,00 \mathrm{Af}$ & $0,13 \pm 0,00 \mathrm{Ad}$ & $1,96 \pm 1,00 \mathrm{Aef}$ \\
& $0,35 \pm 0,04 \mathrm{Ad}$ & $0,00 \pm 0,00 \mathrm{Af}$ & $0,34 \pm 0,01 \mathrm{Ad}$ & $1,59 \pm 0,48 \mathrm{Af}$
\end{tabular}

(1) Média de cinco repetições \pm desvio-padrão da média. Médias seguidas de diferentes letras maiúsculas indicam diferença entre métodos e diferentes letras minúsculas, na coluna, indicam que as amostras diferem entre si, pelo teste de Tukey, a 5\%. 


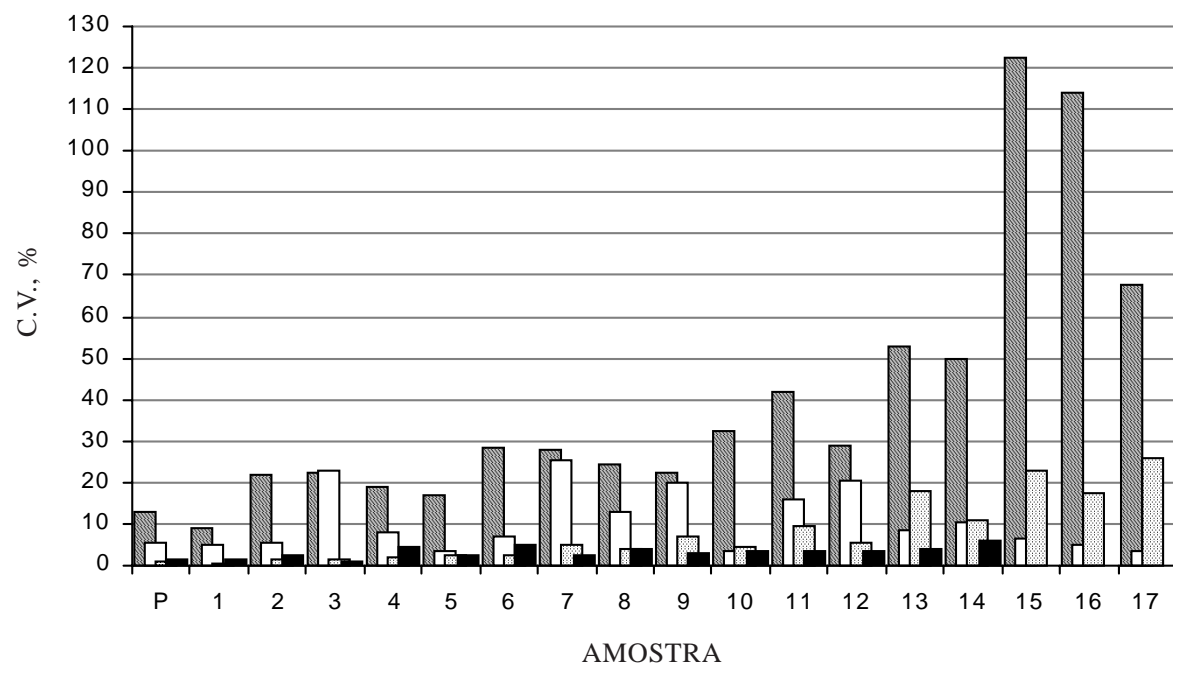

\section{圆 Colorim etria $\square$ Turbidim etria $\square$ Gravim etria $\quad$ E. A. A. \\ Figura 1. Coeficientes de variação, entre cinco repetições, das técnicas de determinação de $S$, aplicadas ao extrato de água régia.}

de Fe nestas soluções, é plausível a ocorrência de precipitado.

Testes realizados nos extratos de água régia indicaram que, a valores de pH em torno de dois, já se verificava a formação de precipitados para as amostras $P, 1,2,3,4,5,7,8,9$ e 10, que continham pirita ou outro mineral de ferro (Quadro 1).

Observa-se, ainda (Quadro 2 e Figura 1), que a técnica colorimétrica, descrita por Palaskar et al. (1981), apresentou o pior desempenho no que se refere à exatidão e precisão, nos extratos avaliados. A amplitude de recuperação, para a amostra-padrão, variou entre 66,01 e $89,84 \%$ do valor teórico de S nos sulfetos de ferro $\left(\mathrm{FeS}_{2}\right)$. De acordo com esta técnica, o pH das alíquotas deveria estar na faixa entre 2,0 e3,0. Conforme mencionado anteriormente, para al gumas amostras aqui estudadas $(P, 1,2,3$, $4,5,7,8,9$ e 10), nesta faixa de $\mathrm{pH}$, ocorreu a formação de precipitado de cor marrom-escura.

N ofim desta etapa do processo analítico, ocorreu a precipitação de óxidos de ferro hidratados, para algumas amostras, bem como a precipitação do $\mathrm{BaSO}_{4}$. Numa etapa posterior, o excesso de cromato de bário foi também precipitado, pela el evação do $\mathrm{pH}$ ao adicionar solução de $\mathrm{NH}_{4} \mathrm{OH}$. Desta forma, acredita-se que o insucesso dessa técnica, quando aplicada a esses substratos, se deve à co-precitação de parte do cromato livre, referente ao sulfato, em meio a tantas precipitações. Segundo Bassett et al . (1978), quando um precipitado se separa de uma solução, nem sempre é puro, podendo conter quantidades variáveis de impurezas, que dependem da natureza do precipitado e das condições de precipitação.
Na tentativa de fundamentar tal hipótese, realizou-se um teste para verificar o nível de recuperação de $\mathrm{S}$ em extratos de água régia e determinação colorimétrica. A fonte de S utilizada foi o $\mathrm{FeSO}_{4}$, sendo a recuperação média da ordem de $89,62 \%$ do $\mathrm{S}$ adicionado e desvio-padrão da média equivalente a 0,76 (C.V. $=1,91 \%$ ). Este valor de S recuperado indica que pode ter ocorrido a coprecipitação. Porém, o desvio-padrão da média e o coeficiente de variação relativamente baixos evidenciam que, caso tenha havido a co-preci pitação de cromato, esta aconteceu de forma consistente entre as cinco repetições avaliadas. Deve-se mencionar, ai nda, que os coeficientes de determi nação apresentados pelas cinco repetições de curvas de calibração, onde se aplicou esta técnica, foram superiores a 0,99 (Quadro 3).

Os resultados obtidos para a técnica col orimétrica sugerem a presença de constituintes nas amostras que levam a resultados pouco confiáveis na determinação de S. Desta forma, além de ser lenta etrabal hosa, essa técnica foi consi derada ineficiente em amostras de rochas e sedimentos.

\section{Teores de $\mathrm{S}$ nos extratos de $\mathrm{H}_{2} \mathrm{O}_{2}$}

Algumas alterações foram aplicadas à técnica descrita por O'Shay et al. (1990) no intuito de adequá-la às amostras aqui estudadas. As amostras utilizadas por O'Shay et al. (1990) apresentavam teores de $\mathrm{S}$ inferiores a $0,5 \mathrm{dag} \mathrm{kg}^{-1}$. Assim sendo, as quantidades de agente oxidante ou de amostra a serem utilizados no tratamento das amostras com teores de $\mathrm{S}$ superiores àquele valor devem ser ajustados. Com base nos resultados de teores totais 
Quadro 3. Curvas de calibração para as determinações de S por colorimetria, conforme proposto por Nemeth (1964) e descrito por PALASKAR et al. (1981)

[S] Rep. 1 Rep. 2 Rep. 3 Rep. 4 Rep. 5

\begin{tabular}{cccccc}
\hline mg L-1 & \multicolumn{5}{c}{ Absorvância } \\
\cline { 2 - 6 } 0,0 & 0,000 & 0,000 & 0,000 & 0,000 & 0,000 \\
4,0 & 0,089 & 0,092 & 0,085 & 0,098 & 0,098 \\
8,0 & 0,199 & 0,186 & 0,195 & 0,185 & 0,198 \\
12,0 & 0,337 & 0,345 & 0,342 & 0,334 & 0,333 \\
16,0 & 0,467 & 0,478 & 0,467 & 0,463 & 0,472 \\
20,0 & 0,606 & 0,605 & 0,610 & 0,607 & 0,617 \\
$\mathrm{R}^{2}$ & 0,994 & 0,992 & 0,993 & 0,991 & 0,993 \\
\hline
\end{tabular}

de S apresentados pelos autores supracitados e dos teores de S, aproximados, nas amostras aqui estudadas, julgou-se mais apropriado alterar a quantidade das amostras, para, então, adequá-las à quantidade deagente oxidanteindicada. Caso fosse alterada a quantidade do oxidante, maior número de alterações deveria ser feito daí por diante, para a execução da técnica. Uma delas seria a quantidade de $\mathrm{Cu}^{2+}$ adicionada para decompor $\mathrm{oH}_{2} \mathrm{O}_{2}$. Segundo O'Shay et al . (1990), o Cu²+éutilizado para catalisar a decomposição do $\mathrm{H}_{2} \mathrm{O}_{2}$. Contudo, em meio aquoso o $\mathrm{Cu}^{2+}$ gera íons $\mathrm{H}^{+}$, conforme a reação descrita por Stumm \& Morgan (1970):

$$
\mathrm{Cu}^{2+}+\mathrm{H}_{2} \mathrm{O} \Leftrightarrow \mathrm{Cu}(\mathrm{OH})^{+}+\mathrm{H}^{+}
$$

Assim, alterando o tamanho das amostras, não seria necessário alterar a quanti dade dos reagentes indicados pelos autores. Além disto, seriam necessários cerca de $15 \mathrm{~L}$ de $\mathrm{H}_{2} \mathrm{O}_{2}$ para oxidar $0,5 \mathrm{~g}$ deamostra-padrão de $\mathrm{FeS}_{2}$ (grau de pureza $\cong 100 \%$ ), pois O'Shay et al. (1990) utilizaram $150 \mathrm{~mL}$ de $_{2} \mathrm{O}_{2}$ para oxidar $0,5 \mathrm{~g}$ de amostra que continha, aproximadamente, 0,5 dag $\mathrm{kg}^{-1}$ de S ou 0,94 dag $\mathrm{kg}^{-1}$ de $\mathrm{FeS}_{2}$.

$\mathrm{Na}$ etapa inicial de preparo das amostras, conforme descrito por O'Shay et al. (1990), mais especificamente na fase de lavagem com $\mathrm{HCl}$ $6,0 \mathrm{~mol} \mathrm{~L}^{-1}$ para eliminar carbonatos e sulfatos porventura presentes na amostra, verificou-se um forte odor de gases sendo eliminados de algumas amostras. Testou-se então a hipótese de perda deS, na forma de gás sulfídrico, nas amostras estudadas. Resultados positivos foram observados para as amostras 5, 6, 7, 8 e 10, todas contendo sulfetos de $\mathrm{Pb}$ ou Zn (Quadro 1).

O processo de liberação de gases desencadeia-se quando o $\mathrm{HCl}$ entra em contato com al guns sulfetos, promovendo a dissolução destes, como é o caso do sulfeto de chumbo (galena) presente na amostra 6:

$$
\mathrm{PbS}+2 \mathrm{HCl} \Leftrightarrow \mathrm{H}_{2} \mathrm{~S} \uparrow+\mathrm{PbCl}_{2}
$$

O resultado positivo, para o teste, foi observado quando $\mathrm{o}_{2} \mathrm{~S}$ desprendido entrou em contato com o acetato de chumbo presente no papel de filtro precipitando-se na forma de sulfeto de chumbo, conforme a reação descrita por Vogel (1974):

$$
\mathrm{Pb}\left(\mathrm{C}_{2} \mathrm{H}_{3} \mathrm{O}_{2}\right)_{2}+\mathrm{H}_{2} \mathrm{~S} \Leftrightarrow \mathrm{PbS} \downarrow+2 \mathrm{CH}_{3} \mathrm{COOH}
$$

Deve-se ressaltar que o $\mathrm{HCl}$ não tem potencial redox suficientemente alto para oxidar o sulfeto a sulfato. O S foi perdido para a atmosfera justamente por manter-sena forma reduzida. Assim, a etapa de lavagem com $\mathrm{HCl} 6,0 \mathrm{~mol} \mathrm{~L}^{-1}$, para amostras que liberaram $\mathrm{H}_{2} \mathrm{~S}$ quando em contato com este ácido, foi suprimida (amostras 5, 6, 7, 8 e 10).

O peróxido de hidrogênio, na dosagem aplicada, mostrou-se pouco eficiente no que se refere à oxidação das amostras estudadas e,ou, aconteceram perdas de S não detectadas durante o processo de oxidação (Quadro 4). A recuperação deS, obtida pela técnica gravimétrica, para a amostra-padrão de $\mathrm{FeS}_{2}$, variou de 57,68 a 71,96\%, em relação ao valor teórico de $\mathrm{S}$. As técnicas turbidimétrica e determinação indireta deS, por meio do Ba remanescente, por EAA nos extratos de $\mathrm{H}_{2} \mathrm{O}_{2}$, apresentaram precisão superior à gravimétrica (Quadro 4), com amplitude de recuperação de $\mathrm{S}$ para a amostra-padrão $(\mathrm{P})$, variando de 51,86 a $53,47 \%$ e 52,09 a $55,40 \%$, respectivamente. Porém, todas as técnicas apresentaram exati dão muito abaixo do esperado.

Deve-se mencionar, ainda, que, ao final do processo de oxidação, as amostras foram filtradas para balão volumétrico de $200 \mathrm{~mL}$ e o material presente no papel defiltro foi lavado com sol ução de $\mathrm{CaCl}_{2}$ 1,0 mol L-1 e o volume final obtido com a mesma solução.

Verificou-se, durante as leituras de Ba, por EAA, que o $\mathrm{CaCl}_{2}$, de alguma forma, poderia estar interferindo, pois foi constatado um intenso acúmulo de sais na fenda do queimador-atomizador do espectrofotômetro, que causava fal has evidentes na chama, tornando-a descontínua. A cada cinco amostras lidas, a chama era apagada para se efetuar a limpeza na fenda do queimador-atomizador. Segundo Skoog \& West (1971), uma das características mais importantes na chama do espectrofotômetro de absor ção atômica é que ela se mantenha estável e apresente comprimento adequado (5 a $10 \mathrm{~cm}$ ) durante o processo de leitura. Quanto mais comprida a chama, maior o número de átomos no trajeto da radiação em condições de realizar uma transição el etrônica.

O peróxido de hidrogênio foi considerado, portanto, inadequado para a oxidação das amostras estudadas, quando o objetivo final foi a determinação de $\mathrm{S}$ nos extratos. 
Quadro 4. Teores de $\mathrm{S}$ determinados por gravimetria, indiretamente por meio do Ba remanescente por EAA, e por turbidimetria, nos extratos de $\mathrm{H}_{2} \mathrm{O}_{2}$

\begin{tabular}{cccc}
\hline Amostra & Gravimetria & Ba remanescente & Turbidimetria \\
\cline { 2 - 4 } & & Média $\pm \mathrm{S}_{\overline{\mathrm{y}}}^{(1)}, \mathrm{dag} \mathrm{kg}^{-1}$ & $28,19 \pm 0,15 \mathrm{Ba}$ \\
$\mathrm{P}$ & $34,65 \pm 1,05 \mathrm{Ac}$ & $28,48 \pm 0,36 \mathrm{Ba}$ & $22,04 \pm 0,49 \mathrm{Bb}$ \\
1 & $46,98 \pm 1,64 \mathrm{Aa}$ & $21,60 \pm 0,43 \mathrm{Bb}$ & $19,87 \pm 0,30 \mathrm{Bbc}$ \\
2 & $44,61 \pm 1,62 \mathrm{Ab}$ & $21,03 \pm 0,31 \mathrm{Bb}$ & $17,96 \pm 0,10 \mathrm{Bc}$ \\
3 & $43,70 \pm 1,86 \mathrm{Ab}$ & $15,83 \pm 0,35 \mathrm{Cc}$ & $10,27 \pm 0,27 \mathrm{Bd}$ \\
4 & $22,91 \pm 1,03 \mathrm{Ad}$ & $10,38 \pm 0,28 \mathrm{Bd}$ & $7,92 \pm 0,18 \mathrm{Bd}$ \\
5 & $14,01 \pm 0,44 \mathrm{Af}$ & $6,38 \pm 0,29 \mathrm{Be}$ & $9,11 \pm 0,14 \mathrm{Bd}$ \\
6 & $18,88 \pm 0,27 \mathrm{Ae}$ & $9,55 \pm 0,45 \mathrm{Bd}$ & $3,31 \pm 0,09 \mathrm{Ae}$ \\
7 & $4,00 \pm 0,55 \mathrm{Ag}$ & $0,53 \pm 0,05 \mathrm{Bf}$ & $2,24 \pm 0,11 \mathrm{Aef}$ \\
8 & $1,96 \pm 0,16 \mathrm{Aghi}$ & $1,48 \pm 0,06 \mathrm{Af}$ & $0,19 \pm 0,00 \mathrm{Af}$ \\
9 & $0,64 \pm 0,54 \mathrm{Ahi}$ & $0,19 \pm 0,02 \mathrm{Af}$ & $1,95 \pm 0,10 \mathrm{Aef}$ \\
10 & $2,01 \pm 0,16 \mathrm{Aghi}$ & $0,14 \pm 0,09 \mathrm{Bf}$ & $0,54 \pm 0,01 \mathrm{Af}$ \\
11 & $0,44 \pm 0,05 \mathrm{Ahi}$ & $0,42 \pm 0,02 \mathrm{Af}$ & $1,64 \pm 0,05 \mathrm{ABef}$ \\
12 & $2,54 \pm 0,22 \mathrm{Agh}$ & $0,27 \pm 0,05 \mathrm{Bf}$ & $0,05 \pm 0,00 \mathrm{Af}$ \\
13 & $0,63 \pm 0,10 \mathrm{Ai}$ & $0,19 \pm 0,02 \mathrm{Af}$ & $0,43 \pm 0,01 \mathrm{Af}$ \\
14 & $0,81 \pm 0,06 \mathrm{Ai}$ & $0,03 \pm 0,02 \mathrm{Af}$ & $0,25 \pm 0,01 \mathrm{Af}$ \\
15 & $0,54 \pm 0,10 \mathrm{Ai}$ & $0,00 \pm 0,00 \mathrm{Af}$ & $0,09 \pm 0,00 \mathrm{Af}$ \\
16 & $0,27 \pm 0,05 \mathrm{Ai}$ & $0,09 \pm 0,01 \mathrm{Af}$ & $0,09 \pm 0,01 \mathrm{Af}$ \\
17 & $0,02 \pm 0,01 \mathrm{Ai}$ & $0,00 \pm 0,00 \mathrm{Af}$ & \\
\hline
\end{tabular}

(1) Média de cinco repetições \pm desvio-padrão da média. Médias seguidas de diferentes letras maiúsculas indicam diferença entre métodos e diferentes letras minúsculas, na coluna, indicam que as amostras diferem entre si, pelo teste de Tukey, a 5\%.

\section{Acidez e "S equivalente" em extratos de $\mathrm{H}_{2} \mathrm{O}_{2}$ e suas relações com Sextraído por água régia e $\mathrm{H}_{2} \mathrm{O}_{2}$}

A partir da reação de oxidação da pirita ou marcassita (Reação 8), seguida pela reação de oxidação do $\mathrm{Fe}^{2+}$ (Reação 9) e da reação de hidrólise do $\mathrm{Fe}^{3+}$ (Reação 10), apresentadas por Singer \& Stumm (1970), verifica-se que $1 \mathrm{~mol}$ de $\mathrm{FeS}_{2}$ $(\mathrm{MM}=119,98)$ produz 4 moles de acidez $\left(\mathrm{H}^{+}\right)$:

$$
\begin{gathered}
\mathrm{FeS}_{2}+7 / 2 \mathrm{O}_{2}+\mathrm{H}_{2} \mathrm{O} \Leftrightarrow \mathrm{Fe}^{2+}+2 \mathrm{SO}_{4}^{2-}+2 \mathrm{H}^{+} \\
\mathrm{Fe}^{2+}+1 / 4 \mathrm{O}_{2}+\mathrm{H}^{+} \Leftrightarrow \mathrm{Fe}^{3+}+1 / 2 \mathrm{H}_{2} \mathrm{O} \\
\mathrm{Fe}^{3+}+3 \mathrm{H}_{2} \mathrm{O} \Leftrightarrow \mathrm{Fe}(\mathrm{OH})_{3}+3 \mathrm{H}^{+}
\end{gathered}
$$

Desta forma, teoricamente, para cada $\mathrm{kg} \mathrm{deFeS}_{2}$, podem ser gerados 33,34 moles de acidez. Portanto, o valor de acidez potencial obtido a partir do extrato de $\mathrm{H}_{2} \mathrm{O}_{2}$, para a amostra-padrão (P) (Quadro 5), foi inferior ao valor máximo teórico. Houve uma recuperação média de $71,85 \%$ da aci dez teórica total . O'Shay et al. (1990) relataram trabalhos que apresentaram eficiência do $\mathrm{H}_{2} \mathrm{O}_{2}$ na oxidação do enxofre variando de 83,6 a 86,2\%, em amostras de ambientes anaeróbicos, e de 22,0 a $94,5 \%$, em amostras de arenito. Ainda, segundo esses autores, o método modificado de determinação da acidez potencial, por eles proposto, apresentou recuperação de sulfetos entre 97 e 102\%, quando aplicado a amostras padrão de pirita.

Verificou-se, ainda, que as amostras $P, 1,2,3,4$ e 5 apresentaram maiores valores de acidez. A amostra 5 apresentou apenas pirita, como mineral gerador de acidez; as demais também apresentaram marcassita em sua constituição. N Neste grupo, a amostra 5 foi a que apresentou menor geração de acidez. Esta contém cal cita e dolomita (Quadro 1), que podem ter neutralizado parte da acidez produzida, uma vez que não foi tratada com $\mathrm{HCl}$ 6,0 $\mathrm{mol} \mathrm{L}^{-1}$, antes da oxidação, para eliminar o carbonato presente, já quemostrou resposta positiva para o teste de liberação de $\mathrm{H}_{2} \mathrm{~S}$.

A amostra 6, rica em galena, revel ou acidez da ordem de $1,24 \mathrm{~mol} \mathrm{~kg}^{-1}$, que contradiz, a princípio, aquilo preconizado por Ingri (1996). Segundo este autor, sulfetos como esfal erita (ZnS), cal cocita (CuS) e galena (PbS), por si só, não apresentam oxidação ácida, conforme se verifica nos seguintes equilíbrios:

$$
\begin{aligned}
& \mathrm{ZnS}+2 \mathrm{O}_{2} \Leftrightarrow \mathrm{Zn}^{2+}+\mathrm{SO}_{4}{ }^{2-} \\
& \mathrm{CuS}+2 \mathrm{O}_{2} \Leftrightarrow \mathrm{Cu}^{2+}+\mathrm{SO}_{4}{ }^{2-} \\
& \mathrm{PbS}+2 \mathrm{O}_{2} \Leftrightarrow \mathrm{Pb}^{2+}+\mathrm{SO}_{4}{ }^{2-}
\end{aligned}
$$

Contudo, a oxidação de qual quer sulfeto insolúvel leva à formação de soluções ácidas, por reações de hidrólise do íon do metal ou por preci pitação de um hidróxido insolúvel. O grau de acidez depende da natureza do metal, particularmente da extensão de sua hidrólise ou da insolubilidade de seu hidróxido (Krauskopf, 1972). SegundoJ ennings et al. (2000), a hidrólise do Pb é possível, de acordo com o seguinte equilíbrio:

$$
\mathrm{Pb}^{2+}+2 \mathrm{H}_{2} \mathrm{O} \Leftrightarrow \mathrm{Pb}(\mathrm{OH})_{2}+2 \mathrm{H}^{+}
$$


Quadro 5. Acidez potencial, nos extratos de $\mathrm{H}_{2} \mathrm{O}_{2}$, determinada por titulometria

\begin{tabular}{cc}
\hline Amostra & {$\left[\mathbf{H}^{+} \mathbf{]}\right.$} \\
\hline & Média $\pm \mathrm{S}_{\overline{\mathrm{y}}}{ }^{(1)}, \mathrm{dag} \mathrm{kg}^{-1}$ \\
$\mathrm{P}$ & $23,95 \pm 0,66 \mathrm{a}$ \\
1 & $9,11 \pm 1,09 \mathrm{~cd}$ \\
2 & $10,04 \pm 0,93 \mathrm{~cd}$ \\
3 & $17,54 \pm 1,21 \mathrm{~b}$ \\
4 & $11,54 \pm 1,02 \mathrm{c}$ \\
5 & $6,34 \pm 2,32 \mathrm{~d}$ \\
6 & $1,24 \pm 0,36 \mathrm{e}$ \\
7 & $0,00 \pm 0,00 \mathrm{e}$ \\
8 & $0,00 \pm 0,00 \mathrm{e}$ \\
9 & $0,00 \pm 0,00 \mathrm{e}$ \\
10 & $0,00 \pm 0,00 \mathrm{e}$ \\
11 & $0,18 \pm 0,03 \mathrm{e}$ \\
12 & $0,26 \pm 0,08 \mathrm{e}$ \\
13 & $0,00 \pm 0,00 \mathrm{e}$ \\
14 & $0,00 \pm 0,00 \mathrm{e}$ \\
16 & $0,02 \pm 0,02 \mathrm{e}$ \\
17 & $0,00 \pm 0,00 \mathrm{e}$ \\
\end{tabular}

(1) Média de cinco repetições \pm desvio-padrão da média. Médias seguidas de diferentes letras minúsculas indicam que as amostras diferem entre si, pelo teste de Tukey, a 5\%.

No entanto, os produtos da oxi dação da gal ena são de baixa sol ubili dadee a subseqüente precipitação do $\mathrm{PbSO}_{4}$ previnea hidrólise do $\mathrm{Pb}^{2+}$ livre Por outrolado, de acordo com Rimstidt et al. (1994), citados por J ennings et al. (2000), a presença do íon $\mathrm{Fe}^{3+}$, no meio em que a galena está sendo oxidada, pode levar à formação de acidez, de acordo com o seguinte equilíbrio:
$\mathrm{PbS}+8 \mathrm{Fe}^{3+}+4 \mathrm{H}_{2} \mathrm{O} \Leftrightarrow \mathrm{Pb}^{2+}+\mathrm{SO}_{4}^{2-}+8 \mathrm{Fe}^{2+}+8 \mathrm{H}^{+}(15)$

A acidez apresentada pela amostra 6 equivale à acidez passível de ser gerada por uma amostra que contenha 3,73 dag kg-1 de FeS 2 . Deve-se lembrar, contudo, que não foram detectados, por difração de raios-X, minerais com Fe nesta amostra (Quadro 2).

Os valores de $\mathrm{S}$ calculados a partir da acidez determinada por titulação dos extratos de $\mathrm{H}_{2} \mathrm{O}_{2}$, seguindo a mesma estequiometria mostrada anteriormente, foram denominados "S equivalente" (Quadro 6). Observando a relação entre "S equivalente" e S total extraído com água régia e determinado, indiretamente, por EAA, notou-se que, para todos os casos em que foi possível executar os cálculos, a relação foi menor que a unidade, indicando, mais uma vez, que o extrator $\mathrm{H}_{2} \mathrm{O}_{2}$, na quantidade utilizada, mostrou-se menos eficiente, para a oxidação dos sulfetos, em relação à água régia.

Deve-se lembrar, contudo, que o cálculo de S a partir da acidez gerada pode levar a uma subestimativa do teor de S realmente presente na amostra, para os casos em que ocorram minerais cuja acidez produzida se deva, em parte, a reações de hidrólise. Este é o caso de minerais como $\mathrm{FeS}_{2}$, quando a hidrólise do Fe não é completa. Conforme já mencionado, a acidez gerada depende da natureza do metal, extensão da hidrólise e insolubilidade do hidróxido formado (Krauskopf, 1972).

Observa-se, ainda, no quadro 6, que as maiores taxas de recuperação de $S$ parecem estar associadas à presença de pirita e marcassita, bem como a

Quadro 6. Teores de "S equivalente" à acidez determi nada nos extratos de $\mathrm{H}_{2} \mathrm{O}_{2}$, comparados com os teores de $\mathrm{S}$, determinados indiretamente por $\mathrm{EAA}$, nos extratos de água régía e $\mathrm{H}_{2} \mathrm{O}_{2}$, pelo método do $\mathrm{Ba}$ remanescente

\begin{tabular}{|c|c|c|c|c|c|}
\hline \multirow{2}{*}{ Amostra } & \multirow{2}{*}{$\begin{array}{c}\text { S equivalente } \\
\qquad \mathrm{H}_{2} \mathrm{O}_{2}\end{array}$} & \multicolumn{2}{|c|}{ S total } & \multicolumn{2}{|c|}{ S equivalente/S total } \\
\hline & & A.R.(1) & $\mathbf{H}_{2} \mathbf{O}_{2}$ & A.R. & $\mathrm{H}_{2} \mathrm{O}_{2}$ \\
\hline & \multicolumn{3}{|c|}{ Média $\pm \mathrm{S}_{\overline{\mathrm{y}}}(2)$, dag $_{\mathrm{kg}}{ }^{-1}$} & & \\
\hline$P$ & $38,40 \pm 1,06$ & $53,04 \pm 0,90$ & $28,48 \pm 0,80$ & 0,72 & 1,35 \\
\hline 1 & $14,60 \pm 1,75$ & $52,40 \pm 0,74$ & $21,60 \pm 0,96$ & 0,28 & 0,68 \\
\hline 2 & $16,09 \pm 1,49$ & $41,69 \pm 0,99$ & $21,03 \pm 0,68$ & 0,39 & 0,77 \\
\hline 3 & $28,12 \pm 1,94$ & $40,57 \pm 0,47$ & $15,83 \pm 0,77$ & 0,69 & 1,78 \\
\hline 4 & $18,50 \pm 1,63$ & $26,16 \pm 1,14$ & $10,38 \pm 0,63$ & 0,71 & 1,78 \\
\hline 5 & $10,16 \pm 3,71$ & $13,24 \pm 0,31$ & $6,38 \pm 0,65$ & 0,77 & 1,59 \\
\hline 6 & $1,99 \pm 0,58$ & $10,12 \pm 0,50$ & $9,55 \pm 1,00$ & 0,20 & 0,21 \\
\hline 7 & $0,00 \pm 0,00$ & $5,16 \pm 0,13$ & $0,53 \pm 0,11$ & 0,00 & 0,00 \\
\hline 8 & $0,00 \pm 0,00$ & $4,70 \pm 0,18$ & $1,48 \pm 0,13$ & 0,00 & 0,00 \\
\hline 9 & $0.00+0.00$ & $3.83+0.11$ & $0.19+0.05$ & 0.00 & 0.00 \\
\hline 10 & $0,00 \pm 0,00$ & $3,07 \pm 0,11$ & $0,14 \pm 0,21$ & 0,00 & 0,00 \\
\hline 11 & $0,28 \pm 0,04$ & $2,87 \pm 0,09$ & $0,42 \pm 0,05$ & 0,10 & 0,68 \\
\hline 12 & $0,42 \pm 0,13$ & $2,78 \pm 0,09$ & $0,27 \pm 0,11$ & 0,15 & 1,56 \\
\hline 13 & $0,00 \pm 0,00$ & $0,72 \pm 0,03$ & $0,19 \pm 0,04$ & 0,00 & 0,00 \\
\hline 14 & $0,00 \pm 0,00$ & $0,20 \pm 0,01$ & $0,03 \pm 0,04$ & 0,00 & 0,00 \\
\hline $\begin{array}{l}14 \\
15\end{array}$ & $0,03 \pm 0,03$ & $0,00 \pm 0,00$ & $0,00 \pm 0,01$ & - & 10,83 \\
\hline 16 & $0,00 \pm 0,00$ & $0,00 \pm 0,00$ & $0,09 \pm 0,03$ & - & 0,00 \\
\hline 17 & $0,01 \pm 0,02$ & $0,00 \pm 0,00$ & $0,00 \pm 0,00$ & - & - \\
\hline
\end{tabular}

${ }^{(1)}$ A.R. = água régia. ${ }^{(2)}$ Média de cinco repetições \pm desvio-padrão da média. 
concentrações relativamente al tas desulfetos, como é o caso das amostras $P, 3,4$ e 5; contudo menores taxas de recuperação deS parecem estar associadas à ausência destes minerais, presença de outros sulfetos e também baixos teores de sulfetos nas amostras, como se verifica para as amostras 7, 8, 9, $10,11,13,14,15,16$ e 17 . As amostras 1 e 2 apresentaram pirita e marcassita em sua constituição, mas a presença de outros sulfetos contribuiu para reduzir a taxa de recuperação de $S$ nestes casos. As amostras 6 e 11 não apresentaram sulfetos de Fe e as taxas de recuperação de $\mathrm{S}$ para estes casos foram relativamente baixas.

\section{Teores $\mathrm{Fe}$ e $\mathrm{Pb}$, extraídos por água régia, e $\mathrm{H}_{2} \mathrm{O}_{2}$, determinados por EAA}

A amplitude de recuperação do Fe nos extratos de água régia, para a amostra-padrão $(P)$, variou de 96,84 a 99,51\%, com relação ao valor teórico total de $\mathrm{Fe}$ contido nos $\mathrm{FeS}_{2}$ (Quadro 7). Contudo, para o $\mathrm{H}_{2} \mathrm{O}_{2}$, a recuperação variou de 1,14 a 3,09\%, para a mesma amostra. Esta baixa taxa de recuperação do Fe, provavel mente, deveu-seao pH mais el evado dos extratos obtidos a partir do $\mathrm{H}_{2} \mathrm{O}_{2}$. Além disso, conforme mencionado anteriormente, aconteceram interferências durantea leitura no espectrofotômetro de absorção atômica, que causaram fal has na chama, quando se utilizou o $\mathrm{H}_{2} \mathrm{O}_{2}$ como extrator.
A amplitude de recuperação do $\mathrm{Pb}$, para a amostra rica em PbS, amostra 6 (Quadro 1), variou de 74,99 a 84,84\%, com relação ao val or teórico total de $\mathrm{Pb}$ contido no $\mathrm{PbS}$, quando o extrator utilizado foi água régia. Contudo, notou-se um baixo nível de recuperação do $\mathrm{Pb}$ onde foi utilizada a técnica descrita por O'Shay et al. (1990), modificada (Quadro 7); evidenciando, novamente, as interferências durante as determinações no espectrofotômetro de absorção atômica e,ou, reações de precipitação do Pb. O objetivo da técnica descrita por O'Shay et al. (1990) foi determinar a acidez gerada por uma amostra e não os teores de S, Fe ou Pb.

Considerando que a massa atômica do $S$ é de 32,064 e do ferro igual a 55,847, tem-se que relação $\mathrm{S} / \mathrm{Fe}$ nas moléculas de $\mathrm{FeS}_{2}$ é de aproximadamente 1,15. Portanto, relações inferiores a 1,15 (Quadro 8), nos extratos de água régia, indicam a presença de outras fontes de ferro, além daquele fornecido pela pirita e marcassita. Esteé o caso das amostras 5, 7, $8,9,10,13,14$ e 15 . Nas amostras 9, 13, 14 e 15, isto se justifica pela ausência de sulfetos de ferro (Quadro 1). Nestes casos, a presença de ferro se deve à jarosita e romerita (amostra 9), calcosiderita (amostra 13) e jarosita (amostras 14 e 15). As amostras 5, 7, 8 e 10, contêm sul fetos como esfalerita e cal copi rita; no entanto, a baixa relação S/Fe, nestes casos, provavelmente deveu-seà presença desiderita

Quadro 7. Teores de $\mathrm{Fe}$ e $\mathrm{Pb}$ nos extratos de água régia e $\mathrm{H}_{2} \mathrm{O}_{2}$ determinados por EAA

\begin{tabular}{|c|c|c|c|c|}
\hline \multirow{2}{*}{ Amostra } & \multicolumn{2}{|c|}{$\mathbf{F e}$} & \multicolumn{2}{|c|}{$\mathbf{P b}$} \\
\hline & Água régia & $\mathrm{H}_{2} \mathrm{O}_{2}$ & Água régia & $\mathrm{H}_{2} \mathrm{O}_{2}$ \\
\hline & \multicolumn{2}{|c|}{ 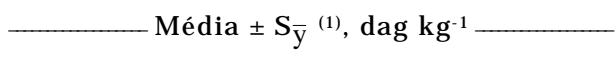 } & \multicolumn{2}{|c|}{$\longrightarrow$ Média $\pm S_{\bar{y}}^{(1)}, g ~ k g^{-1}$} \\
\hline$P$ & $45,86 \pm 0,21 \mathrm{Aa}$ & $0,98 \pm 0,15 \mathrm{Ba}$ & $0,00 \pm 0,00 \mathrm{Aa}$ & $0,00 \pm 0,00 \mathrm{Aa}$ \\
\hline 1 & $27,47 \pm 0,19 \mathrm{AC}$ & $0,48 \pm 0,22 \mathrm{Ba}$ & $0,10 \pm 0,09 \mathrm{Aa}$ & $0,10 \pm 0,06 \mathrm{Aa}$ \\
\hline 2 & $24,02 \pm 0,88 \mathrm{Ad}$ & $0,46 \pm 0,05 \mathrm{Ba}$ & $0,03 \pm 0,00 \mathrm{Aa}$ & $0,47 \pm 0,20 \mathrm{Aa}$ \\
\hline 3 & $31,92 \pm 1,00 \mathrm{Ab}$ & $0,32 \pm 0,02 \mathrm{Ba}$ & $0,10 \pm 0,01 \mathrm{Aa}$ & $0,00 \pm 0,00 \mathrm{Aa}$ \\
\hline 4 & $14,43 \pm 0,21 \mathrm{Af}$ & $0,19 \pm 0,01 \mathrm{Ba}$ & $0,00 \pm 0,00 \mathrm{Aa}$ & $0,06 \pm 0,03 \mathrm{Aa}$ \\
\hline 5 & $17,47 \pm 0,39 \mathrm{Ae}$ & $0,05 \pm 0,01 \mathrm{Ba}$ & $0,07 \pm 0,00 \mathrm{Aa}$ & $0,08 \pm 0,08 \mathrm{Aa}$ \\
\hline 6 & $0,15 \pm 0,01 \mathrm{Ak}$ & $0,01 \pm 0,01 \mathrm{Aa}$ & $688,23 \pm 14,84 \mathrm{Ab}$ & $18,32 \pm 3,67 \mathrm{Ba}$ \\
\hline 7 & $17,25 \pm 0,20 \mathrm{Ae}$ & $0,00 \pm 0,00 \mathrm{Ba}$ & $0,02 \pm 0,00 \mathrm{Aa}$ & $0,04 \pm 0,03 \mathrm{Aa}$ \\
\hline 8 & $12,23 \pm 0,14 \mathrm{Afg}$ & $0,00 \pm 0,00 \mathrm{Ba}$ & $0,03 \pm 0,02 \mathrm{Aa}$ & $0,02 \pm 0,02 \mathrm{Aa}$ \\
\hline 9 & $6,09 \pm 0,16 \mathrm{Ah}$ & $0,00 \pm 0,00 \mathrm{Ba}$ & $0,06 \pm 0,00 \mathrm{Aa}$ & $0,02 \pm 0,01 \mathrm{Aa}$ \\
\hline 10 & $11,21 \pm 0,37 \mathrm{Ag}$ & $0,00 \pm 0,00 \mathrm{Ba}$ & $0,00 \pm 0,00 \mathrm{Aa}$ & $0,01 \pm 0,01 \mathrm{Aa}$ \\
\hline 11 & $1,08 \pm 0,06 \mathrm{Ajk}$ & $0,00 \pm 0,00 \mathrm{Aa}$ & $0,04 \pm 0,00 \mathrm{Aa}$ & $0,00 \pm 0,00 \mathrm{Aa}$ \\
\hline 12 & $2,42 \pm 0,05 \mathrm{Aijk}$ & $0,01 \pm 0,00 \mathrm{Ba}$ & $0,10 \pm 0,01 \mathrm{Aa}$ & $0,01 \pm 0,01 \mathrm{Aa}$ \\
\hline 13 & $1,76 \pm 0,04 \mathrm{Aijk}$ & $0,00 \pm 0,00 \mathrm{Ba}$ & $0,06 \pm 0,01 \mathrm{Aa}$ & $0,01 \pm 0,01 \mathrm{Aa}$ \\
\hline 14 & $1,41 \pm 0,03 \mathrm{Ajk}$ & $0,00 \pm 0,00 \mathrm{Aa}$ & $0,03 \pm 0,02 \mathrm{Aa}$ & $0,02 \pm 0,01 \mathrm{Aa}$ \\
\hline 15 & $0,60 \pm 0,01 \mathrm{Ak}$ & $0,00 \pm 0,00 \mathrm{Aa}$ & $0,01 \pm 0,01 \mathrm{Aa}$ & $0,02 \pm 0,01 \mathrm{Aa}$ \\
\hline 16 & $3,82 \pm 0,08 \mathrm{Ahi}$ & $0,00 \pm 0,00 \mathrm{Ba}$ & $0,00 \pm 0,00 \mathrm{Aa}$ & $0,01 \pm 0,00 \mathrm{Aa}$ \\
\hline 17 & $3,08 \pm 0,02 \mathrm{Aij}$ & $0,00 \pm 0,00 \mathrm{Ba}$ & $0,01 \pm 0,01 \mathrm{Aa}$ & $0,00 \pm 0,00 \mathrm{Aa}$ \\
\hline
\end{tabular}

(1) Média de cinco repetições \pm desvio-padrão da média. Médias seguidas de diferentes letras maiúsculas indicam diferença entre métodos e diferentes letras minúsculas, na coluna, indicam que as amostras diferem entre si, pelo teste de Tukey, a 5\%. 
Quadro 8. Teores de S, Fe e $\mathrm{Pb}$ e relação $\mathrm{S} / \mathrm{Fe}$ e $\mathrm{S} / \mathrm{Pb}$ nos extratos de água régia, determinados por EAA, o S determinado indiretamente, por meio do Ba remanescente

\begin{tabular}{|c|c|c|c|c|c|}
\hline Amostra & $\mathbf{s}$ & $\mathrm{Fe}$ & $\mathbf{P b}$ & $\mathrm{S} / \mathrm{Fe}$ & $\mathbf{S} / \mathbf{P b}$ \\
\hline & \multicolumn{3}{|c|}{ - Média $\pm \mathrm{S}_{\overline{\mathrm{y}}}^{(1)}$, dag kg-1 } & & \\
\hline$P$ & $53,04 \pm 0,40$ & $45,86 \pm 0,21$ & $0,00 \pm 0,00$ & 1,16 & - \\
\hline 1 & $52,40 \pm 0,33$ & $27,47 \pm 0,19$ & $0,01 \pm 0,01$ & 1,91 & $5.282,77$ \\
\hline 2 & $41,69 \pm 0,44$ & $24,02 \pm 0,88$ & $0,00 \pm 0,00$ & 1,74 & $13.896,00$ \\
\hline 3 & $40,57 \pm 0,21$ & $31,92 \pm 1,00$ & $0,01 \pm 0,00$ & 1,27 & $4.148,72$ \\
\hline 4 & $26,16 \pm 0,51$ & $14,43 \pm 0,21$ & $0,00 \pm 0,00$ & 1,81 & - \\
\hline 5 & $13,24 \pm 0,14$ & $17,47 \pm 0,39$ & $0,01 \pm 0,00$ & 0,76 & $1.833,01$ \\
\hline 6 & $10,12 \pm 0,22$ & $0,15 \pm 0,01$ & $68,82 \pm 1,48$ & 66,32 & 0,15 \\
\hline 7 & $5,16 \pm 0,06$ & $17,24 \pm 0,20$ & $0,00 \pm 0,00$ & 0,309 & $2.579,50$ \\
\hline 8 & $4,70 \pm 0,08$ & $12,23 \pm 0,14$ & $0,00 \pm 0,00$ & 0,38 & $1.565,33$ \\
\hline 9 & $3,83 \pm 0,05$ & $6,09 \pm 0,16$ & $0,01 \pm 0,00$ & 0,63 & 619,49 \\
\hline 10 & $3,07 \pm 0,05$ & $11,21 \pm 0,37$ & $0,00 \pm 0,00$ & 0,27 & - \\
\hline 11 & $2,87 \pm 0,04$ & $1,08 \pm 0,06$ & $0,00 \pm 0,00$ & 2,66 & 955,33 \\
\hline 12 & $2,78 \pm 0,04$ & $2,42 \pm 0,05$ & $0,01 \pm 0,00$ & 1,15 & 289,78 \\
\hline 13 & $0,72 \pm 0,01$ & $1,76 \pm 0,04$ & $0,01 \pm 0,00$ & 0,41 & 113,52 \\
\hline 14 & $0,21 \pm 0,01$ & $1,41 \pm 0,03$ & $0,00 \pm 0,00$ & 0,14 & 66,00 \\
\hline 15 & $0,00 \pm 0,00$ & $0,56 \pm 0,01$ & $0,00 \pm 0,00$ & 0,00 & - \\
\hline 16 & $0,00 \pm 0,00$ & $3,82 \pm 0,08$ & $0,00 \pm 0,00$ & 0,00 & - \\
\hline 17 & $0,00 \pm 0,00$ & $3,08 \pm 0,02$ & $0,00 \pm 0,00$ & 0,00 & - \\
\hline
\end{tabular}

(1) Média de cinco repetições \pm desvio-padrão da média.

e calcosiderita. Resultados superiores a 1,15 (Quadro 8) indicam a presença de outros minerais sulfetados, como se verificou, claramente, na amostra 6, cuja caracterização mineralógica (Quadro 1) indicou a presença de galena (PbS).

Apesar do teor de $\mathrm{S}$ próximo ao valor teórico máximo para os $\mathrm{FeS}_{2}$ na amostra 1 (Quadro 2), verificou-se uma recuperação média de $27,47 \%$ de Fe. A presença de cal copirita $\left(\mathrm{CuFeS}_{2}\right)$ e esfalerita (ZnS) justifica a alta relaçãoS/Fe de 1,91 (Quadro 8), obtida para essa amostra. Também, para as amostras 2, 3, 4 e 11, a relação S/Fe foi superior ao valor teórico esperado para $\mathrm{FeS}_{2}$. I sto pode ser atribuído à presença de outros sulfetos, como esfalerita, cal cocita, eà presença do sulfato de ferro, denominado coquimbita $\left(\mathrm{Fe}_{2}\left(\mathrm{SO}_{4}\right)_{3} \cdot 9 \mathrm{H}_{2} \mathrm{O}\right)$, na amostra 2 (Quadro 1).

A relação S/Fe apresentada no quadro 8 para a amostra-padrão de $\mathrm{FeS}_{2}$, muito próximo ao valor teórico, confirmou os resultados anteriores quanto à qualidade desta amostra e exatidão da técnica de determinação de $\mathrm{Fe}$ e $\mathrm{S}$, ambos por EAA, após digestão por água régia.

A relação S/Pb para uma amostra pura de PbS é de aproximadamente 0,16 . A amostra 6 apresentou relação S/Pb equivalentea 0,15 (Quadro 8), próxima à teórica, que confirmou a presença de galena (Quadro 1). À semel hança do que foi discutido para as relações S/Fe, valores para relação S/Pb superiores a 0,16 indicam a presença de outras fontes de S na amostra que não apenas PbS. Relações inferiores a 0,16 revelam a presença de outras fontes de $\mathrm{Pb}$, além do PbS.

\section{CONCLUSÕES}

1. As técnicas de maior exatidão para a determinar os sulfetos, nos extratos de água régia, foram a gravimetria e a determinação indireta do S, por meio do Ba remanescente por EAA, e a turbidimetria. As duas primeiras também apresentaram maior precisão, apesar de não diferirem estatisticamente da turbidimetria.

2. A técnica colorimétrica, aplicada aos extratos deágua régia, apresentou menor precisão. A taxa de recuperação dos sulfetos também foi menor, sobretudo nas amostras com al tos teores de enxofre.

3. As taxas de recuperação do $\mathrm{S}$ e a acidez determinada após oxidação da amostras com $\mathrm{H}_{2} \mathrm{O}_{2}$ foram menores em relação aos valores teóricos, indicando não ser este extrator eficiente para a oxidação total dos sulfetos.

4. A gravimetria apresentou baixa recuperação dos sulfetos, porém superior à turbidimetria e à determinação indireta do $\mathrm{S}$, por meio do $\mathrm{Ba}$ remanescente por EAA nos extratos de $\mathrm{H}_{2} \mathrm{O}_{2}$ da amostra-padrão. 
5. A determinação indireta do S, por EAA do Ba remanescente, em extratos deágua régia, mostrou ser a técnica mais indicada para avaliar o teor de sul fetos, tendo em vista sua maior precisão, principalmente para amostras com baixos teores. Apesar de satisfatória, a técnica gravimétrica foi considerada lenta e laboriosa.

\section{AGRADE CIMENTOS}

À F undação deAmparo à Pesquisa do Estado de Minas Gerais (FAPEMIG), pelo auxílio financeiro. AoConsel ho Nacional de Desenvol vimento Científico e Tecnológico (CNPq), pela bolsa de estudos concedida ao primeiro autor. Aos professores Evaldo R. Soares, da Universidade da Região da Campanha (URCAMP), Bagé (RS) e Walter A. P. Abrahão, da Universidade Federal deViçosa (UFV), Viçosa (MG), pelo auxílio na coleta das amostras utilizadas no trabalho.

\section{LITE RATURA CITADA}

ALVAREZV., V.H.; DIAS, L.E.; RIBEIRO J R., E.S.; SOUZA, R.B. \& FONSECA,C.A. Métodos de análises de enxofreem sol os e plantas. Viçosa, UniversidadeFederal deViçosa. 2001. 131p.

ASPIRAS, R.B.; KEENEY,D.R. \& CHESTERS, G. Determination of reduced inorganic sulfur forms as sulfide zinchydrochloric acid distillation. Anal. Lett., 5:425-432. 1972.

BASSETT, J .; DENNEY, R.C.; J EFFERY, G.H. \& MENDHAM, J . Análiseinorgânica quantitativa. Rio deJ aneiro, Guanabara Dois, 1978. 690p.

BLANCHAR, R.W.; RHEN, G. \& CALDWELL, A.C. Sulfur in plant materials by digestion with nitric and perchoric acid. Soil Sci. Soc. Proc., 29:71-72, 1965.

BEATON, J.D.; BURNS, G.R. \& PLATOU, J. Determinations of sulphur in soils and plant material. Washington, 1968. (Tech. Bull, 14)

INGRI, J . Acid mine drainage and environmental monitoring: a short introduction for mineengineers. Lulea-Sweden, Lulea University of Technology, 1996. 39p.

J ENNINGS, S.R.; DOLLHOPF, D.J . \& INSKEEP, W.P. Acid production from sulfide minerals using hydrogen peroxide weathering. App. Geoch., 15:247-255. 2000.
JOINT COMMITTEE ON POWDER DIFRACTION STANDARDS - J CPDS. Selected powder diffraction data for minerals. Pennsylvania, 1974. 833p.

J OHSON, C.M. \& NISHITA, H. Microestimation of sulfur in plant material, soil, and irrigation water. Anal. Chem., 24:736-742, 1952.

KRAUSKOPF, K.B. Introdução à geoquímica. São Paulo, Polígono, 1972. 735p.

LINDSAY, W.L. Chemical equilibria in soil. New York, J ohn Wiley \& Sons, 1979. 439p.

MELLO, J.W.V. \& ABRAHÃO W.A.P. Geoquímica da drenagem ácida. In: DIAS, L.E. \& MELLO, J.W.V. Recuperação de áreas degradadas. Viçosa, Folha de Viçosa, 1978. p.45-57.

O'SHAY,T.; HOSSNER, L.R. \& DIXON J .B. A Modified hydrogen peroxide oxidation method for determination of potential acidity in pyritic overburden. J. Environ. Qual., 19:778782. 1990.

PALASKAR, M.S.; BABREKAR, P.G. \& GHOSH, A.B. A rapid analytical technique to estimate sulphur in soil and plant extracts. J. Ind. Soc. Soil Sci., 29:249-256, 1981.

SKIAVON, G. \& ZOTTI, G. Eletrochemical detection of traceshydrogen sulfide in gaseous samples by porous silver electrodes supported on ion-exchange membranes (solid polymer electrolytes). Anal. Chem., 67:318-323, 1995.

SINGER, P.E. \& STUMM, W. Acid mine drainage: the rate determining step. Sci., 167:1121-1123, 1970.

SKOOG, D.A. \& WEST, D.M. Principles of instrumental analysis. New York, Holt, Rinehart and Winston, 1971. 710p.

STUM, W. \& MORGAN, J.J. Aquatic Chemistry. New York: J ohn Wiley \& Sons, 1970. 345p.

SOARES, E.R. Mobilização de metais pesados em materiais provenientes do complexo carboenergético de Candiota-RS. Viçosa, Universidade Federal de Viçosa, 1995. 95p. (Tese de Mestrado)

SORENSEN, D.L.; KNEIB, W.A. \& PORCELLA, D.B. Determination of sulfide in pyritic soil and minerals with a sulfide ion electrode. Anal. Chem., 51:1870-1872, 1979.

TSE, YU-H.; J ANDA, P.; LAM, H. \& LEVER, A.B.P. Electrode with electropolymerizad tetraaminophthalocyanatocobalt (II) for detection of sulfide ion. Anal. Chem., 67:981-985, 1995.

VOGEL,A.I. Quimica analitica cualitativa. 5. ed. Buenos Aires, Kapelusz, 1974. 635p. 
M.L.T. CORRÊA et al. 